\title{
THE EXISTENCE OF GENE DEOXYRIBONUCLEIC ACID POLYMERASE MUTATION FROM POSITIVE HEPATITIS B SAMPLES IN BANDUNG, INDONESIA
}

\author{
TINA ROSTINAWATI ${ }^{*}$, DEBBIE SOFIE RETNONINGRUM ${ }^{2}$, DESI PRATIWI ${ }^{1}$
}

${ }^{1}$ Department of Biological Pharmacy, Pharmaceutics, Faculty of Pharmacy, Universitas Padjadjaran, Indonesia. ${ }^{2}$ Department of Biological Pharmacy, Pharmaceutics, School of Pharmacy, Institut Teknologi Bandung, Indonesia. Email: t_rostinawati@unpad.ac.id

Received: 06 November 2016, Revised and Accepted: 24 January 2017

\section{ABSTRACT}

Objective: The objective of the study is to complete mutation existence in reverse transcriptase (RT) domain of the viral polymerase.

Methods: The study was done by amplification step of viral polymerase gene fragment, agarose gel electrophoresis, polymerase chain reaction product purification with GFX column kit, sequencing, and sequencing result analysis. The samples were derived from clinical laboratory in Bandung Indonesia.

Results: The result showed mutations in deoxyribonucleic acid (DNA) fragment encoding for RT domain viral polymerase in sample 6, 7, and 8. There were mutations leading to amino acid substitution L526S in sample 6, D551E in sample 7, and D552E in sample 8.

Conclusion: D551E and D552E substitution occurred in YMDD motif RT DNA polymerase that produced YMDE mutant. L526S, D551E, and D552E were estimated as antivirus-resistance mutants that have never been reported before.

Keywords: Hepatitis B virus, Mutation, Gene encoding for reverse transcriptase deoxyribonucleic acid polymerase.

(C) 2017 The Authors. Published by Innovare Academic Sciences Pvt Ltd. This is an open access article under the CC BY license (http://creativecommons. org/licenses/by/4. 0/) DOI: http://dx.doi.org/10.22159/ajpcr.2017.v10s2.19493

\section{INTRODUCTION}

Hepatitis B virus (HBV) infection is a major human health problem with a mortality rate of 1.2 million deaths per year worldwide due to this disease. HBV infection is characterized by a high rate of development of chronic infection with either high- or low-titer viremia. HBV infection causes acute and chronic liver disease, including chronic hepatitis, cirrhosis, and liver cancer (hepatocellular carcinoma) $[1,2]$.

Various attempts have been made to suppress the development of HBV infections, including antiviral drug development and development of an HBV vaccine, but there is no effective antiviral treatment for patients chronically infected with HBV. Treatment with interferon is quite beneficial for most patients infected with chronic HBV but is limited to an overall average response of $<40 \%$ since dosages of interferon are usually limited because of side effects.

Replication of HBV deoxyribonucleic acid (DNA) takes place through reverse transcription of intermediate ribonucleic acid pre-genomically. It is the basis for the development of nucleoside analogs that inhibit the activity of HBV reverse transcriptase (RT), such as lamivudine, famciclovir, and others as an alternative to interferon therapy [1-3].

Lamivudine has been shown to suppress HBV replication and has few side effects and is used to treat chronic HBV infection. Lamivudine can also prevent reinfection after liver transplantation. The use of lamivudine for long-term treatment is reported to cause the occurrence of viral resistance. In $14 \%$ of patients treated with lamivudine for 1 year, an amino acid substitution occurred in the tyrosine-methionineaspartate-aspartate (YMDD) motif in the C domain of HBV DNA polymerase (HDP) at codon 552, either methionine into valine (M552V) or methionine into isoleucine (M552I). Another amino acid substitution in B domain of HDP, i.e., the substitution of leucine into methionine at codon 528 (L528M), was also reported to be coincident with the amino acid substitution in the YMDD motif. L528M amino acid substitutions are common in patients treated with famciclovir $[1,2,4]$.
In addition to mutations in the gene encoding the HDP region that result in viral resistance, HBV may also have mutations in the gene encoding a surface antigen (HBsAg) protein that gives rise to the phenomenon of vaccine-escape mutants. Vaccine-escape mutants are not recognized by any anti-HBsAg antibodies, so it can infect people who have been vaccinated. A study showed that vaccine-escape mutants had been found in clinical isolate samples from four cities in Java, Indonesia. Vaccine-escape mutants were derived from substitutions originally reported from Yogyakarta (M133T) and Jember (G145R), as well as a nucleotide substitution/insertion that was seen in samples from Jakarta (at codon 117 and the insertion between codons 136 and 137) (data not reported)

Information about mutations in the genes encoding HDP and HBsAg thus becomes one of the important factors in the treatment and prevention of HBV infection. The existence of HBV mutants can be determined by analysis of the HBV nucleotide sequence. Determination of nucleotide sequences was performed using polymerase chain reaction (PCR), a technique for replicating DNA in vitro. PCR is used to amplify specific regions of DNA, which can be a single gene, part of a gene, or a noncoding sequence. Primers to initiate the PCR reaction are generally short fragments (20-30 bp) of DNA [5].

\section{METHODS}

The ethical committee approval was provided by Medical Faculty of Universitas Padjadjaran, and 12 participants were included in this study.

\section{HBV isolates}

Samples that used in this research were HBV isolates. HBV isolates were obtained from the main clinical laboratory Paramita Bandung branch, Indonesia to be used as HBV templates for gene amplification. The HBV templates used were HBV DNAs isolated from plasma of chronic Hepatitis B patients through a quantitative HBV PCR examination conducted by the clinical laboratory Paramita Bandung branch. HBV DNA templates had high titer (Table 1). 


\section{Amplification of genes encoding HDP fragment}

DNA samples were amplified in a 96-well thermal cycler instrument with PCR conditions as follows: Initial denaturation $94^{\circ} \mathrm{C}$ for 5 minutes; a reaction cycle consisting of denaturation at $94^{\circ} \mathrm{C}$ for 1 minute, annealing at $47^{\circ} \mathrm{C}$ for 1 minute, and elongation at $72^{\circ} \mathrm{C}$ for 1 minute. Amplification was performed for 35 cycles, and elongation for the last cycle was at $72^{\circ} \mathrm{C}$ for 10 minute. The primers used were BCfwd $25^{\prime}$ ACT CCT GCT CAA GGA ACC TC3 and polymerase BCrev 5' AGA TGT TGT ACA GAC TTG GC3. These primer pairs can amplify fragments of gene encoding RT HDP, which includes codons that encode YMDD motif. Up to $5 \mathrm{ml}$ of a sample of HBV isolate was mixed with Taq buffer solution (1.5 mM MgCl , Tris [pH 8.3] $10 \mathrm{mM}, 50 \mathrm{mM} \mathrm{KCl}$, and gelatin $200 \mathrm{mg} / \mathrm{ml}$ ), $200 \mu \mathrm{M}$ dNTPs, Taq polymerase $5 \mathrm{U}, 1 \mathrm{ml}$ of $30 \mathrm{pmol} \mathrm{BCfwd}$ primer, $1 \mathrm{ml}$ of $30 \mathrm{pmol} \mathrm{BCrev}$ primer, and $25 \mathrm{mM} \mathrm{MgCl}$, then $\mathrm{ddH}_{2} \mathrm{O}$ was added to bring to $25 \mathrm{ml}$.

\section{Purification of PCR product}

An Illustra GFX PCR DNA and Gel Band Purification kit (Amersham Bioscience, Freiburg, Germany) was used to purify the resultant PCR product. Briefly, DNA fragment that was in the gel predefined weight was added capture buffer with volume as much as $10 \mathrm{ml}$ to $10 \mathrm{mg}$. This mixture was incubated at $60^{\circ} \mathrm{C}$ until the gel was dissolved then was centrifuged at $3000-4000 \mathrm{rpm}$ for 30 seconds. The dissolved sample was inserted into the GFX column, incubated for 1 minute at room temperature, then was centrifuged at $12,000 \mathrm{rpm}$ for 1 minute. The filtrate in collection tube was discarded. A total of $500 \mathrm{ml}$ of wash buffer was added to the column, incubated, and then centrifuged back. The filtrate was in the collection tube was again discarded, and the GFX column inserted into a sterile $1.5 \mathrm{ml}$ Eppendorf tube, to which was added $50 \mathrm{ml}$ of elution buffer, then incubated for 1 minute at room temperature and centrifuged at $5000 \mathrm{rpm}$ to obtain purified PCR product.

\section{Determination of nucleotide sequence}

Nucleotide sequence determination was carried out by the Sanger dideoxy method. A sequencing primer has the ability to determine the nucleotide sequence of sample from $5^{\prime}$ to 3 '. Primer sequencing used BCfwd 5' ACT CCT GCT CAA GGA ACC TC3' and BCrev 5' AGA TGT TGT ACA GAC TTG GC 3'. PCR products were purified with sequencing primer, Taq buffer, Taq Polymerase, dNTPs, ddNTPs, and stop solution (95\% formamide; $20 \mathrm{mM}$ EDTA pH 8.0; 0.05\% bromophenol blue, $0.05 \%$ xylene silanol FF). Determination of the nucleotide sequence used an automatic DNA sequencer.

\section{Analysis of nucleotide sequence}

The results of nucleotide sequence determination were analyzed by aligning the nucleotide sequence obtained with the nucleotide sequence encoding the HDP gene fragment in the GenBank. These samples were also analyzed with the nucleotide sequence fragments of the genes encoding HBsAg subtype adw, adr, ayw, and ayr in the GenBank. Amino acid determination was also carried out by the deduction method, manually comparing the results with the partial amino acid sequence

Table 1: HBV isolate sample

\begin{tabular}{lll}
\hline No & Sample code & Titer $(\mathrm{UI} / \mathrm{ml})$ \\
\hline 1 & $2 \mathrm{~A}$ & $1.10 \times 10^{8}$ \\
2 & $2 \mathrm{~B}$ & $3.23 \times 10^{6}$ \\
3 & 4 & $1.74 \times 10^{7}$ \\
4 & $6 \mathrm{~A}$ & $6.82 \times 10^{6}$ \\
5 & $6 \mathrm{~B}$ & $1.96 \times 10^{6}$ \\
6 & 7 & $3.13 \times 10^{6}$ \\
7 & 12 & $3.85 \times 10^{7}$ \\
8 & 14 & $3.51 \times 10^{7}$ \\
9 & 17 & $4.15 \times 10^{7}$ \\
10 & 20 & $5.37 \times 10^{7}$ \\
11 & 21 & $1.06 \times 10^{7}$ \\
12 & $19 \mathrm{M}$ & $1.60 \times 10^{7}$ \\
\hline
\end{tabular}

of the RT DNA polymerase and the protein S - HBsAg. Genotype isolates were determined by comparing the results of the determination of nucleotide sequences homologous to the nucleotide sequence of data obtained from GenBank, using Basic Local Alignment Search Tool (BLAST) (www.ncbi.nlm.nih.gov) [6].

\section{RESULTS AND DISCUSSION}

\section{Amplification of gene encoding the HDP fragment}

The gene fragment encoding HDP was amplified using BCfwd and BCrev primers, with size of the PCR product \pm 240 bp. PCR products showed the DNA bands between $200 \mathrm{bp}$ and $300 \mathrm{bp}$ of the marker. Gene fragments from all of the isolate samples were successfully amplified, with DNA band size also $\pm 240 \mathrm{bp}$. The results of electrophoresis of PCR products can be seen in Fig. 1.

\section{Determination of nucleotide sequence}

To determine nucleotide sequence, only nine samples were sequenced; three samples were insufficient concentration (data not shown) for nucleotide sequence determination (data not shown).

\section{Analysis of nucleotide sequence}

BLAST results showed that the homology of nine samples were $90-99 \%$ based GeneBank database (Table 2). Samples with code 2B, 4, 6A, 6B, $7,12,20$, and 21 showed the nucleotide sequence of the gene encoding HDP genotype B, while sample with code 14 showed $99 \%$ homology with genotype E. Genotype differences were based on $8 \%$ intergroup diversity of the entire genome or $4.1 \%$ diversity of gene encoding surface protein. Genotype B is one of the eight genotypes of HBV spread across Asia, including Indonesia, while the E genotype is more common in the African region [7].

The alignment results showed that three samples (samples with code 7,12 , and 14) had changed in their HDP nucleotide sequences. The results of the alignment of the HDP sequences can be seen in Fig. 2. HDP also has reverse transcription activity and thus does not have a proofreading activity, allowing the occurrence of mutations with high frequency of between $10^{-5}$ to $10^{-6}$ per nucleotide per day. The result is accumulation of compounded nucleotide sequence variations, some of which can occur during antiviral therapy. In addition, fluctuations in the concentration of intracellular dNTP causes hypermutation, such as [dTTP]/[dCTP] changes G to A [7].

Since mutations to the nucleotide sequence may or may not cause changes in amino acids composition in the resultant protein, the alignment process was also performed on the HDP amino acid sequence. The nucleotide sequences coding genes of HDP and nine samples were translated into amino acids using DNA translate tools (https://www.expasy.org). Alignment of amino acid sequences of HBV isolates samples to the wild-type HBV sample were also done using the BLAST program of NCBI site. The result of the amino acid alignment of nine samples shown in Fig. 3.

Sample with code 7 showed a nucleotide sequence change at position 1577 , a changed of a $\mathrm{T}$ (thymine) to a C (cytosine), which caused an

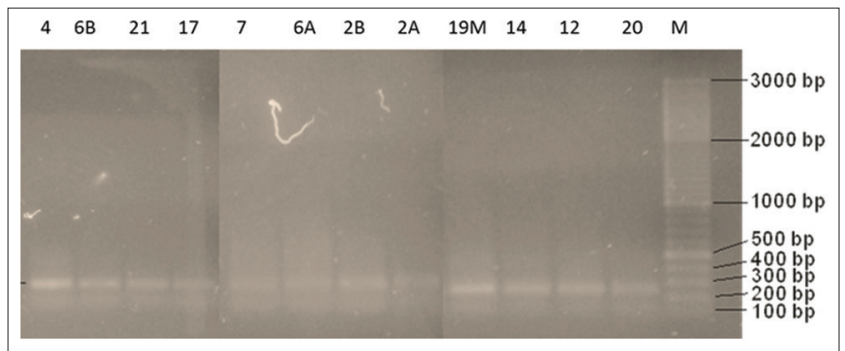

Fig. 1: Amplification of fragment of gene encoding hepatitis B virus deoxyribonucleic acid polymerase 
Table 2: BLAST results of nucleotide sequence samples

\begin{tabular}{lll}
\hline Sample code & BLAST result (Result identity) & $\begin{array}{l}\text { GeneBank } \\
\text { Access number }\end{array}$ \\
\hline 2B & HBV genotype B & X98077 \\
4 & HBV genotype B & X98077 \\
$6 \mathrm{~A}$ & HBV genotype B & X98077 \\
$6 \mathrm{~B}$ & HBV genotype B & $\mathrm{X} 98077$ \\
7 & HBV genotype B & $\mathrm{X} 98077$ \\
12 & HBV genotype B & $\mathrm{X} 98077$ \\
14 & HBV genotype E & $\mathrm{X} 75657$ \\
20 & HBV genotype B & $\mathrm{X} 98077$ \\
21 & HBV genotype B & $\mathrm{X} 98077$ \\
\hline
\end{tabular}

HBV: Hepatitis B virus, BLAST: Basic Local Alignment Search Tool

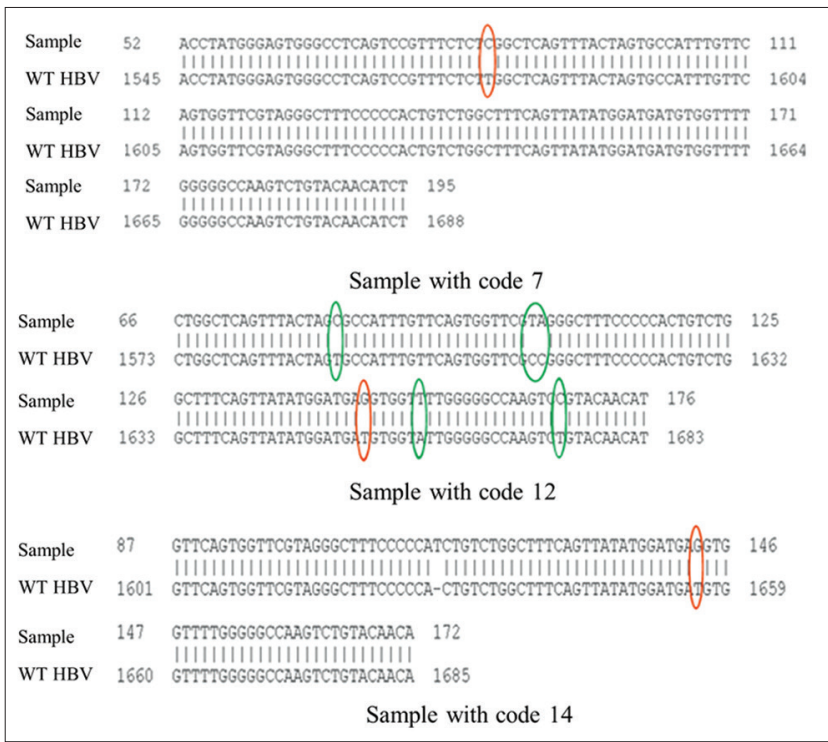

Fig. 2: Alignment of nucleotide sequences of samples to wild-type hepatitis B virus nucleotide sequence

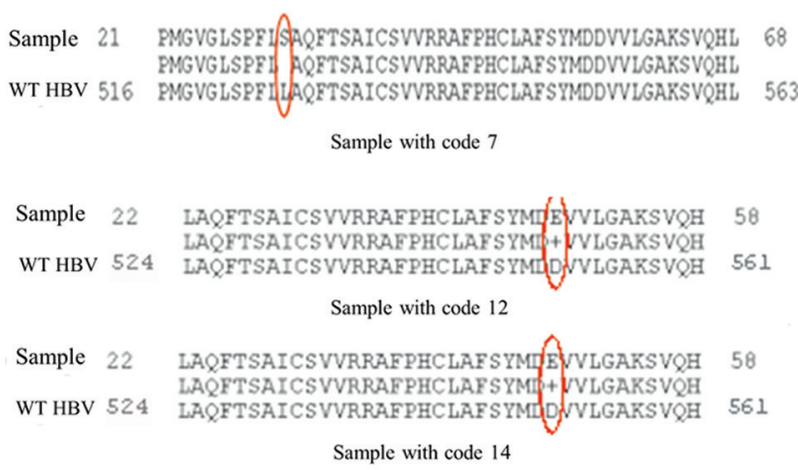

Sample 21 PMGVGLSPFISAQETSAICSVVRRAFPHCLAFSYMDDVVGARSVQHL 68 PMGVGLSPEI AOFTSAICSVVRRAFPHCLAFSYMDDVVLGARSVQHL WT HBV 516 PMGVGLSPF 4 AQFTSAICSVVRAFPHCLAFSTMDDVVLGARSVQHL 563

Sample with code 7

Sample 22 LAQFTSAICSVVRRAFPHCLAFSYMI El/VLGARSVQH LAQFTSAICSVVRRAFPHCLAFSYM + VVLGAKSVQH WT HBV 524 LAQFTSAICSVVRRAFPHCLAF SYMLDVVLGAKSVQH 561 Sample with code 12

Sample 22 LAQFTSAICSVVRRAFPHCLAF SYMI BVVLGARSVQH LAQFTSAICSVVRRAFPHCLAF SYM + VVLGAKSVQH WT HBV 524 LAQFTSAICSVVRRAFPHCLAF SYMLDVVLGARSVQH 561

Sample with code 14

Fig. 3: Alignment of amino acid sequences of samples to wild-type hepatitis $B$ virus amino acid sequence

amino acid substitution of leucine (L) to serine (S) at codon 526. This amino acid residue lies in the B domain of HBV RT polymerase. Mutations in this domain are often associated with the phenomenon of resistance to nucleoside analogs. The type of mutation that had been previously reported in this position was an L526M substitution, which often coincided with the emergence of an M550V substitution in the YMDD motif (C-domain). The combination of both substitutions provides a resistance effect stronger than a single substitution. The combination of substitutions caused a 15-fold decreased sensitivity to the nucleoside analog lamivudine. The B domain is involved in the placement of the DNA template during DNA replication. In the process, the $\mathrm{B}$ and $\mathrm{C}$ domain interact, such mutations that occur in the $\mathrm{B}$ domain will compensate for imperfections in the C domain $[8,9]$.

Leucine and serine have different characteristics. Leucine has alkyl side chain branching, thereby providing more of a non-polar nature, whereas serine is an amino acid containing polar hydroxyl groups on its side chains. Differences in the nature of this amino acid likely affect the protein's affinity to a DNA template, such that a single mutation that occurs in this position is sufficient to provide the effect of resistance to nucleoside analogs. Codon 526, 551, and 552 lie within a region of the gene encoding HDP that overlaps with the gene encoding HBsAg near determinant "a." Mutation at codon 526 of HDP had changed TrpArg in HBV surface protein as well as mutation at codon 551 and 552 had substituted Met-Arg at the same protein. The determinant "a" in $\mathrm{S}$ protein is responsible for the immune response to HBsAg, so the mutations that occur in the area can lower affinity in vitro against antiHBs in the HBV vaccine $[10,11]$

Analysis of sample with code 12 showed a change in nucleotide sequence at five positions, i.e., T1590C, C1611T, T1653G, A1659T, and T1674C. The mutations at position 1590, 1611, 1659, and 1674 were not accompanied by amino acid changes, so these mutations were silent. The change of thymine (T) to guanine (G) at position 1653 caused aspartic acid (D) to change to glutamate acid (E) at codon 551, in the gene encoding HDP. Both amino acids have similar properties, both acidic and polar. The difference is that glutamic acid has one more carbon atom than aspartic acid, such that glutamic acid is slightly more non-polar. This mutation changed the YMDD motif in the $C$ domain of HDP to YMDE. The YMDD motif is catalytic for the RT activity of DNA polymerase, involved in nucleotide binding to the viral replication process. It has been widely reported that mutations in the YMDD motif will change the activity of RT thereby reducing the ability of the mutant to replicate. However, some amino acid substitutions in the YMDD motif are capable of inducing resistance to the nucleoside analog lamivudine. Lamivudine is a cytidine analog that effectively inhibits viral replication by suppressing the activity of RT through its action as a chain terminator. Mutations in the YMDD motif alter the conformation of the catalytic site of RT activity. The glutamic acid molecule is bigger and acts as a steric hindrance thus inhibiting the binding of lamivudine at the RT nucleotide binding site [12-14]. The substitution YMDE was also seen in sample with code 14 at codon 552; the different position of this codon is due to genotypic difference in genome length. Furthermore, homology model of HDP structure is not done because sequence homology between HDP and HIV-1 RT, usually used as a template for HDP, is less from 30\% [15]. Hence, binding affinity between L526S, D551E, and D552E of HDP cannot be predicted.

These L526M, D551E, and D552E amino acid substitutions seen here have not been previously reported. Various YMDD variants have been reported, i.e., YIDD, YVDD, YADD, YLDD, YKDD, YRDD, and YTDD [12].

\section{CONCLUSION}

Amino acid substitutions, i.e., L526M, D551E, and D552E were in areas of the HB DNA polymerase protein with RT activity, especially the YMDD motif (D551E and D552E), which are important for viral replication. The location of these mutations, the active site of RT activity, is an important target in the treatment of hepatitis B; thus, mutations that occur in this area can reduce the sensitivity of the virus to nucleoside analogs and lead to the development of resistance to these antiviral drugs.

\section{ACKNOWLEDGMENT}

This study was funded by "Hibah Pekerti” Research Grant Indonesia

\section{REFERENCES}

1. Ono-Nita SK, Kato N, Shiratori Y, Masaki T, Lan KH, Carrilho FJ, et al. YMDD motif in hepatitis B virus DNA polymerase influences on replication and lamivudine resistance: A study by in vitro full-length viral DNA transfection. Hepatology 1999;29(3):939-45. 
2. Seignères B, Pichoud C, Ahmed SS, Hantz O, Trépo C, Zoulim F. Evolution of hepatitis $B$ virus polymerase gene sequence during famciclovir therapy for chronic hepatitis B. J Infect Dis 2000;181(4):1221-33.

3. Lazarevic I. Clinical implications of hepatitis B virus mutations: Recent advances. World J Gastroenterol 2014;20(24):7653-64.

4. Yuen MF, Sablon E, Hui CK, Yuan HJ, Decraemer H, Lai CL. Factors associated with hepatitis B virus DNA breakthrough in patients receiving prolonged lamivudine therapy. Hepatology 2001;34(4):785-91.

5. Sambrook J, Russell DW. Molecular Cloning: A Laboratory Manual. $3^{\text {rd }}$ ed. New York: Cold Spring Harbor Laboratory Press; 2001.

6. León B, Taylor L, Vargas M, Luftig RB, Albertazzi F, Herrero L, et al. $\mathrm{HBx}$ M130K and V131I (T-A) mutations in HBV genotype F during a follow-up study in chronic carriers. Virol J 2005;2:60.

7. Stuyver LJ, Locarnini SA, Lok A, Richman DD, Carman WF, Dienstag JL, et al. Nomenclature for antiviral-resistant human hepatitis $\mathrm{B}$ virus mutations in the polymerase region. Hepatology 2001;33(3):751-7.

8. Santos EA, Sucupira MV, Arabe J, Gomes SA. Hepatitis B virus variants in an HIV-HBV co-infected patient at different periods of antiretroviral treatment with and without lamivudine. BMC Infect Dis 2004;4:29.

9. Nakanishi H, Kurosaki M, Asahina Y, Onuki Y, Ueda K, Nishimura Y, et al. Polymerase domain B mutation is associated with hepatitis relapse during long-term lamivudine therapy for chronic hepatitis B. Intervirology 2005;48(6):381-8.

10. Bottecchia M, Souto FJ, O KM, Amendola M, Brandão CE, Niel C, et al. Hepatitis B virus genotypes and resistance mutations in patients under long term lamivudine therapy: Characterization of genotype $\mathrm{G}$ in Brazil. BMC Microbiol 2008;8:11

11. Simon B, Kundi M, Puchhammer E. Analysis of mutations in the $\mathrm{S}$ gene of hepatitis B virus strains in patients with chronic infection by online bioinformatics tools. J Clin Microbiol 2013;51(1):163-8.

12. Pei F, Ning JY, You JF, Yang JP, Zheng J. YMDD variants of HBV DNA polymerase gene: Rapid detection and clinicopathological analysis with long-term lamivudine therapy after liver transplantation. World J Gastroenterol 2005;11(18):2714-9.

13. Damerow H, Yuen L, Wiegand J, Walker C, Bock CT, Locarnini S, et al. Mutation pattern of lamivudine resistance in relation to hepatitis $\mathrm{B}$ genotypes: Hepatitis B genotypes differ in their lamivudine resistance associated mutation pattern. J Med Virol 2010;82(11):1850-8.

14. Tan YW, Ge GH, Zhao W, Gan JH, Zhao Y, Niu ZL, et al. YMDD motif mutations in chronic hepatitis B antiviral treatment naïve patients: A multi-center study. Braz J Infect Dis 2012;16(3):250-5.

15. Daga PR, Duan J, Doerksen RJ. Computational model of hepatitis B virus DNA polymerase: Molecular dynamics and docking to understand resistant mutations. Protein Sci 2010;19(4):796-807. 